\title{
ANÁLISE DE RENDIMENTO ATLÉTICO EM APLICAÇÃO DO MÉTODO DE PERIODIZAÇÃO ATR PARA NADADORES DE PROVAS DE 100 METROS NADO LIVRE
}

\author{
Renato Francisco Rodrigues Marques \\ Thamy Guazelli Ambrósio \\ Gabriela Fabrega Menin \\ Orival Andries Junior
}

\section{Resumo}

A periodização ATR tem como essência a periodicidade e troca de orientação preferencial do treinamento de acordo com o objetivo estabelecido por períodos. Estas trocas se conseguem alternando em três mesociclos: acumulação, transformação e realização, nos quais é esperado que os atletas tenham uma evolução crescente frente à sua performance. Este estudo tem como objetivo analisar a expectativa frente ao método quanto à evolução no resultado dos atletas na prova de 100 metros livre, em diferentes fases do treinamento de nadadores com faixa etária entre quatorze e vinte anos de idade. As análises mostraram uma evolução positiva no resultado dos nadadores, atingindo suas melhores performances respectivamente no mesociclo de realização.

\section{Palavras-Chave}

Natação; Periodização; Treinamento esportivo.

\section{ANALYSIS OF ATHLETICAL INCOME IN APPLICATION OF THE METHOD OF PERIODIZATION ATR FOR SWIMMERS OF TESTS OF 100 METERS I SWIM EXEMPTS}

Renato Francisco Rodrigues Marques

Thamy Guazelli Ambrósio

Gabriela Fabrega Menin

Orival Andries Junior

\begin{abstract}
The structuring ATR has the essence and the frequency of exchange of preferential orientation training in accordance with the objective set by periods. They can be alternating in three mescals: accumulation, processing and implementation, in which it is expected that athletes have a growing trend opposite to their performance. This study aimed to examine the expectation front of the method on the developments in the outcome of athletes in the race of 100 meters in free competitions during the different stages of periodization. The analysis showed a trend in the outcome of the swimmers, reaching its best performance respectively in mescal of achievement
\end{abstract}

\section{Key-Words}

Swimming; Periodization; Sport training. 


\section{INTRODUÇÃO}

A competição esportiva constitui o ápice do processo de treinamento, não só sintetizando os resultados do treinamento desportivo, mas também apresentando meios objetivos para avaliar sua efetividade e assim obter a um bom desempenho.

Visando uma melhor compreensão, Bompa (2001) refere-se à competição como a ocasião na qual o atleta tem a oportunidade de demonstrar seus atributos. No caso da natação competitiva pode ser num confronto entre dois ou mais competidores ou em uma disputa contra o tempo em busca de um índice ou até mesmo um recorde. A competição de natação pode ser considerada como o momento em que todos os nadadores, seja na prova individual ou por equipe, se confrontam para buscar um mesmo objetivo, ou seja, a vitória, e para que isso ocorra existem vários fatores determinantes que fazem parte de um processo. Esse processo engloba vários planejamentos entre eles o do treinamento e junto a isso se consideram de forma especial as qualidades individuais dos atletas.

Assim, se faz necessário estabelecer um processo de treinamento, buscando de acordo com o objetivo, um desenvolvimento lógico e seqüencial das habilidades do individuo respeitando sua individualidade. Essa sistematização do treinamento é denominada de Periodização do Treinamento Desportivo (BOMPA, 2002).

O planejamento do treinamento é o processo cientifico e metodológico que auxilia o atleta a atingir alto nível de rendimento e conseqüentemente um alto desempenho. É o instrumento mais importante que o treinador possui. Se bem estruturado fornece direção, sentido e alvo para o que deve vir a ser realizado. É essencial mencionar que o programa de treinamento baseia-se objetivamente no desempenho do atleta, no seu progresso em todos os períodos e fatores do treinamento e principalmente num bom rendimento na principal competição do ano com uma boa forma atlética (NAVARRO, 1994).

Segundo Navarro (1994), existem diferentes conceitos e classificações de como elaborar e realizar a periodização no treinamento. Um conceito alternativo de classificação é a estruturação ATR, onde sua essência é na periodicidade e a troca de orientação preferencial do treinamento, que se alternam em três diferentes tipos de mesociclos: Acumulação, que diz respeito ao ganho geral da capacidade aeróbica e anaeróbica; Transformação, que é o foco na melhora da potência aeróbica e anaeróbica; e a Realização, 
com intensidade muito próxima do ritmo de prova, visando a competição.

A estrutura ATR baseia-se em dois aspectos fundamentais, primeiramente na concentração de cargas de treinamento sobre capacidades especificas ou objetivos de treinamento concretos, e baseia-se também no desenvolvimento consecutivo de certas capacidades e objetivos em blocos de treinamento especializados ou mesociclos.

A periodização tem como função unir todas as situações que norteiam os atletas e as que constituem o programa de treinamento. É como elaborar um planejamento detalhado baseando no fato de saber que qualquer atleta não mantém permanentemente um alto nível de rendimento, e para se ter uma boa performance no objetivo principal é preciso saber determinar bem o calendário em relação aos princípios da estruturação da periodização do treinamento.

Sendo assim, o objetivo deste estudo é analisar as variações de rendimento dos atletas durante as diferentes fases de treinamento durante o processo de periodização do método ATR, durante suas três diferentes fases, analisando se estes obterão os rendimentos esperados, ou seja, evoluindo a cada fase.

O trabalho se justifica pelo fato da natação ser considerada uma modalidade esportiva que cresceu muito nas últimas décadas, assim como os níveis de competitividade e performance de atletas, tendo a periodização do treinamento um papel importante na preparação dos atletas. Um estudo dessa natureza pode trazer benefícios e contribuições para um treinamento do atleta de natação. Além disso, poderá proporcionar aos profissionais de Educação Física, informações mais apuradas e atualizadas sobre o assunto, o que poderá vir a contribuir para uma melhor habilitação profissional para trabalhar com essa população.

A metodologia se baseia num estudo de campo utilizando a estruturação ATR referenciado por Navarro (1994). Será realizada uma análise sobre a evolução dos resultados dos atletas em competições durante as diferentes fases da periodização do treinamento de nadadores com faixa etária entre quatorze e vinte anos de idade da Associação de Pais e Atletas da Natação da cidade de Bragança Paulista (APAN). A prova escolhida para análise é a de 100 metros nado livre, utilizando como competições intermediárias os torneios da Associação Regional de Natação e como objetivo principal a Copa São Paulo de Vinculados, organizada pela Federação Aquática Paulista.

Conexões: revista da Faculdade de Educação Física da UNICAMP, Campinas, v. 7, n. 2, p. 64-78, maio/ago. 2009. 
$\overline{\mathrm{O} \text { trabalho se compõe de três itens, sendo o primeiro voltado ao universo competitivo da natação, } \mathrm{o}}$ segundo ligado referencial teórico da periodização em ATR, o terceiro à análise de dados e reflexão sobre a relação entre periodização e resultados obtidos.

\section{PERIODIZAÇÃO DO TREINAMENTO}

"Periodização é o planejamento geral e detalhado do tempo disponível para o treinamento, de acordo com os objetivos intermediários perfeitamente estabelecidos respeitando princípios científicos do treinamento desportivo" (DANTAS, 1995, p. 57).

A periodização é um dos mais importantes conceitos do planejamento do treinamento. Esse termo origina-se da palavra período, que é uma porção ou divisão do tempo em pequenos segmentos, que proporcionam maior facilidade em controlar denominadas fases do processo (BOMPA, 2002).

Sob este aspecto, o mesmo autor acrescenta que a periodização refere-se a dois importantes aspectos: periodização do plano anual, dividida em fases menores, tornando o planejamento do treinamento mais seguro e fácil para garantir o desempenho máximo nas principais competições; e periodização das capacidades biomotoras, que provém de um curto período pré-competitivo e refere-se à estruturação das fases de treinamento para que sejam atingidos os maiores níveis possíveis de força, velocidade e resistência.

Segundo Matveev (1997), para a organização do trabalho a ser aplicado sobre os atletas, se faz fundamental a elaboração de um planejamento levando em consideração vários fatores. O calendário de competições durante $\mathrm{o}$ ano tem grande influência na elaboração do treinamento, porém não pode constituir como única base fundamental do planejamento. Outros fatores influenciam nessa elaboração, por exemplo a readaptação do atleta aos treinos e período de férias, condições climáticas, entre outros.

Todo período é composto por micro e macrociclos, cada um dos quais de acordo com o objetivo especifico, derivado dos objetivos gerais do treinamento. Assim, o desempenho depende da adaptação do atleta, do seu ajuste psicológico à competição e treinamento, além de desenvolvimento de suas habilidades e capacidades.

Segundo Bompa (2002), a idéia de periodização consiste em subdividir um período específico de Conexões: revista da Faculdade de Educação Física da UNICAMP, Campinas, v. 7, n. 2, p. 64-78, maio/ago. 2009. 
treinamento em: macrociclo, que pode ser em períodos menores ou fases, chamados microciclos, ou ainda mesociclos que é o caso da estruturação ATR.

\section{ESTRUTURAÇÃO ATR: ACUMULAÇÃO, TRANSFORMAÇÃO E REALIZAÇÃO}

Um conceito alternativo de classificação dos mesociclos proposto por Navarro (1994) diferencia três tipos: acumulação, transformação e de realização. Sua essência radica na periodicidade e a troca da orientação preferencial do treinamento, estas trocas ocorrem através da alternância desses três tipos de mesociclos. Segundo o mesmo autor, a estruturação do treinamento ATR baseia-se em dois pontos fundamentais: A concentração de cargas de treinamento sobre capacidades específicas ou objetivos concretos de treinamento; Desenvolvimento consecutivo de certas capacidades e objetivos em blocos de treinamento especializados ou mesociclos.

A essência do conceito de periodização alternativa reside na freqüência e na comutação da orientação preferencial da formação. Isso é realizado na alternação entre três tipos de mesociclos: acumulação (A), transformação $(\mathrm{T})$ e realização $(\mathrm{R})$.

A orientação e natureza desses mesociclos é um reflexo do seu nome. Assim, mesociclo acumulação é feito com o objetivo de aumentar o potencial motor do atleta e criar uma reserva de base qualidades. É, por outras palavras, as atividades de preparação em miniatura de um mesociclo. O mesociclo chamado de transformação tem o potencial de se tornar uma formação especial, baseando-se numa força desenvolvida, onde aumenta a resistência da força, e sob o desenvolvimento aeróbico ocorre o abastecimento energético misto, ou seja, aeróbio e anaeróbico, aumentando a resistência especial e a velocidade. Por último, o mesociclo de realização cria condições prévias para as competições em que cristalizam potenciais motores acumulados e processados (NAVARRO, 1994).

Segundo o mesmo autor, a estrutura ATR possui características que podem se resumir da seguinte maneira (NAVARRO, 1994):

- Sequencialização de mesociclos baseados na supercompensação dos efeitos do treinamento residuais. Como o treinamento aeróbio e a força máxima possuem o maior efeito residual, estes tipos de treinamento devem ser a base sobre a intensificação da ação posterior. O treinamento deve começar com o desenvolvimento das capacidades com o maior efeito residual. A seguinte 
fase deve centralizar-se no desenvolvimento das capacidades de efeitos residuais médios (força resistência e capacidade anaeróbia). O mesociclo final de realização deve utilizar as cargas de menos efeito residual (cargas anaeróbias aláticas, competição, etc).

- A organização de diferentes macrociclos. A estrutura dos diferentes macrociclos sempre apresenta a seguinte organização de mesociclos concentrados: 1 - Acumulação, 2 - Transformação, 3 Realização. A concentração de uma determinada orientação de carga de treinamento em atletas de elite fica assegurada com um $40 \%$ da totalidade de trabalho. O resto da carga do mesociclo fica distribuído em cargas de outra orientação dentro das que ocupam um lugar de destaque do trabalho anterior realizado.

- A distribuição racional dos macrociclos dentro do plano anual dependerá do número e duração de cada um, da fase específica dentro da temporada, da qualificação do atleta e da especificidade do esporte.

Segundo Navarro (1994), no mesociclo de acumulação é onde ocorrem exercícios de força máxima, que são as bases para novos programas de formação especializada, ou seja, a melhoria de força explosiva e resistência. Além disso, a acumulação servirá para estimular a hipertrofia muscular, o que por vezes é necessário na natação. No entanto, esse trabalho deve ser complementado com o de treinamento aeróbio, para que assim possa melhorar o potencial oxidativo acumulado e contratura dos músculos. Este trabalho deverá ser simultaneamente compatível com os períodos de sofisticação da técnica, eliminando os erros e assim por diante.

Assim, o programa de treinamento deste mesociclo apresenta um montante substancial de carga aeróbica e de trabalho técnico. Deve-se exercer uma força de carga elevada de tal modo que afete a melhoria do sistema nervoso e mecanismos hipertróficos de força de uma forma conjunta.

Para Navarro (1994), todas as competições desportistas exigem e envolvem endurance aeróbico e anaeróbico-aeróbico bem como a resistência especifica. Assim, a melhor forma de combinar a formação da melhoria dessas capacidades é dentro de mesociclo de transformação. Esta formação intensa, em alta demanda, afeta a estabilidade e causa fadiga, que por sua vez, dificulta a técnica. O mesociclo de transformação se caracteriza por carga máxima e acumulação de fadiga, numa quantidade essencial para formações implementadas em estados fadigados. 
De acordo com Navarro (1994), no mesociclo de realização é onde a condição física integrada é trabalhada visando velocidade e táticas competitivas. Assim, a maior parte da formação inclui atividades correspondentes às táticas e técnicas. Adicionalmente, a formação inclui exercícios anaeróbicos-alácticos. Esse trabalho é a maneira eficaz para a realização coerente e especifica para preparação de futuras competições.

Para impulsionar as capacidades de velocidade, que exige que os atletas encontrem-se num estado bem descansado, este mesociclo trabalha em especial o anaeróbico alático, e no caso de nadadores fundistas, ou provas de longas distancias isso não ocorre.

Navarro (1995) apud Garcia Manso (1996) propõe um exemplo da estrutura ATR para nadadores de 100metros livre:

\section{QUADRO 1 - Exemplo da estruturação ATR para nadadores de 100 metros livre}

\begin{tabular}{|c|c|c|}
\hline \multirow{3}{*}{ Acumulação } & Força básica & $\begin{array}{l}\text { Hipertrofia e coordenação intramuscular Exercícios com } \\
\text { pesos e maquina para os grupos musculares importantes. }\end{array}$ \\
\hline & Resistência básica & $\begin{array}{l}\text { Aeróbio leve, médio, intenso. Resistência aeróbia de força. } \\
\text { Tolerância ao lactato. }\end{array}$ \\
\hline & $\begin{array}{l}\text { Exercícios básicos de } \\
\text { técnica }\end{array}$ & $\begin{array}{l}\text { Exercícios básico de estilo, só pernas e braços. Dentro das } \\
\text { tarefas de treinamento de resistência básica. }\end{array}$ \\
\hline \multirow{3}{*}{ Transformação } & Força específica & Forças resistentes de curta duração (0:20 e 1:20) \\
\hline & Resistência específica & $\begin{array}{l}\text { Tolerância ao lactato. Máxima produção de lactato }(0: 45 \text { e } \\
1: 30) \text {. }\end{array}$ \\
\hline & $\begin{array}{l}\text { Exercícios de técnica } \\
\text { em situações de } \\
\text { fadiga }\end{array}$ & $\begin{array}{l}\text { Exercícios básicos do estilo, só perna, só braço, estilo } \\
\text { completo com e ou sem carga adicional. }\end{array}$ \\
\hline \multirow{3}{*}{ Realização } & $\begin{array}{l}\text { Capacidade } \\
\text { velocidade }\end{array}$ & Potência e capacidade anaeróbica alática. \\
\hline & $\begin{array}{l}\text { Treinamento } \\
\text { competitivo }\end{array}$ & $\begin{array}{l}\text { Ritmo de competição e séries quebradas de } 100 \text { metros livre. } \\
\text { Inutação de } 100 \text { metros competitivo. }\end{array}$ \\
\hline & Técnica competitiva & $\begin{array}{l}\text { Afinamento da técnica em situação competitiva em } \\
\text { treinamentos e competição. }\end{array}$ \\
\hline
\end{tabular}

Fonte: Adaptado de NAVARRO (1995) apud GARCIA MANSO (1996).

\section{MATERIAL E MÉTODO}

Este estudo se baseou em metodologia investigativa de campo, que contou com as seguintes fases: coleta de dados, acesso ao resultado dos nadadores e a seus respectivos períodos da periodização do 
treinamento; tratamento de dados, identificação, tempo e número de braçadas dos atletas; e por fim, analise de dados e desenvolvimento de conclusões.

Participantes: $\mathrm{O}$ estudo foi realizado com quinze nadadores de nível estadual, com faixa etária de 10 a 20 anos, sendo dez do sexo masculino e cinco do feminino, da Associação de pais e amigos da natação da cidade de Bragança Paulista. Os nadadores treinam, com sessões de duas horas, por cinco dias na semana, em uma piscina de 25 metros aquecida em temperatura entre 25 e 28 graus celsius. Todos eles foram treinados com base na periodização ATR. A análise se deu durante o processo de um macrociclo com duração de 6 meses.

Foram analisados todos os sujeitos da equipe que nadaram a prova de 100 metros nado livre, sendo este um grupo que represente $100 \%$ dos atletas dentro do padrão desejado para a pesquisa.

Foram recolhidos o tempo da prova total e o parcial a cada 25 metros, além do número de braçadas totais e parciais (contagem realizada a olho nu, sem auxílio de filmagens) nas provas de 100 metros, nado livre dos nadadores em três diferentes competições, sendo cada uma das coletas no final de cada mesociclo da periodização ATR. Com esses dados, foi realizada uma comparação dos tempos nas três competições, para analisar a evolução de performance dos mesmos.

\section{RESULTADOS E DISCUSSÃO}

Serão apresentados os resultados dos atletas de forma individual e coletiva. A análise ocorrerá nas Tabelas 1, 3 e 5 sobre seu tempo parcial e total das provas, e nas de número 2, 4 e 6, sobre seus números parciais e totais de braçadas. Num terceiro momento, ocorrerá a análise do grupo como um todo e tendências de evolução.

Porém, é preciso considerar, para uma análise mais apropriada, que os primeiros 25 metros são, de fato, mais rápidos e contam com menos braçadas devido à maior capacidade de propulsão e deslize da técnica de saída em salto do bloco. Da mesma forma, nos últimos 25 metros são contabilizadas mais braçadas devido ao fato de não haver virada no momento da chegada e, com isso, os atletas realizarem um ciclo a mais para o toque final na parede da piscina.

Dessa forma, tem-se ainda a análise de número de braçadas específicas da soma das porções 2 e 3 da

Conexões: revista da Faculdade de Educação Física da UNICAMP, Campinas, v. 7, n. 2, p. 64-78, maio/ago. 2009. 
prova, ou seja, das partes de nado entre os 25 e 50 metros e entre os 50 e 75 metros.

TABELA 1 - Tempos de nado: mesociclo de acumulação

\begin{tabular}{|c|c|c|c|c|c|}
\hline Atleta/Tempo & $25 m$ & $50 \mathrm{~m}$ & $75 m$ & $100 \mathrm{~m}$ & Total \\
\hline Atleta A & $13^{\prime \prime 91}$ & $16^{\prime \prime} 43$ & $16^{\prime \prime} 61$ & $17^{\prime \prime} 06$ & $1^{\prime} 04^{\prime \prime} 01$ \\
\hline Atleta B & $15 " 42$ & $17 ' 18$ & $18^{\prime \prime} 38$ & $18 "$ "69 & $1^{\prime} 09^{\prime \prime} 67$ \\
\hline Atleta C & $14{ }^{\prime} 31$ & $16 " 60$ & 18 '10 & 18,33 & $1^{\prime} 07^{\prime \prime} 34$ \\
\hline Atleta D & $14 " 64$ & $16 " 56$ & $17 ', 61$ & $17 " ' 82$ & $1^{\prime} 06^{\prime \prime} 63$ \\
\hline Atleta E & $13 " 90$ & 16 '37 & $17^{\prime \prime} 28$ & $17 " 31$ & $1^{\prime} 05^{\prime \prime} 06$ \\
\hline Atleta F & $18^{\prime \prime} 09$ & $21^{\prime \prime} 81$ & 22 '’27 & 22 '’ 75 & $1 ' 24^{\prime \prime} 62$ \\
\hline Atleta $G$ & $17^{\prime \prime} 76$ & $18^{\prime \prime} 68$ & 19 '”1 & 19 '"93 & 1'16"'98 \\
\hline Atleta $\mathbf{H}$ & $20 " 50$ & $26 " 59$ & $27 '>71$ & $28, " 07$ & $1^{\prime} 43^{\prime \prime} 57$ \\
\hline Atleta I & $14 \times 91$ & $17^{\prime \prime} 76$ & 18 '39 & $18^{\prime \prime} 96$ & $1^{\prime} 10^{\prime \prime} 02$ \\
\hline Atleta $\mathbf{J}$ & 20 '25 & $27 \times 25$ & $28{ }^{\prime \prime} 28$ & 29 '” 05 & $1^{\prime} 44^{\prime \prime} 83$ \\
\hline Atleta K & $12 ’ 75$ & 15,39 & $15, ' 39$ & 15 '93 & $59 " 42$ \\
\hline Atleta $L$ & $18 " 43$ & $24{ }^{\prime} 30$ & 26 '’78 & 26,33 & $1 ' 35^{\prime \prime} 84$ \\
\hline Atleta M & $17^{\prime} 75$ & $22 " 57$ & $23 " ' 48$ & $23 " 48$ & $1^{\prime} 27^{\prime \prime} 28$ \\
\hline Atleta $\mathbf{N}$ & $14{ }^{\prime \prime} 79$ & $16^{\prime \prime} 48$ & $166^{\prime} 91$ & $17 ’ 07$ & $1^{\prime} 02^{\prime \prime} 25$ \\
\hline Atleta $O$ & $17 ' 84$ & $19 " 48$ & 20 '27 & 20 "95 & $1^{\prime} 18^{\prime \prime} 54$ \\
\hline MÉDIA & $16^{\prime \prime} 35$ & $19^{\prime \prime} 78$ & $20 " 72$ & $20^{\prime \prime} 78$ & 1'17'64 \\
\hline
\end{tabular}

TABELA 2 - Números de braçadas: mesociclo de acumulação

\begin{tabular}{ccccccc}
\hline Atleta/Tempo & $\mathbf{2 5 m}$ & $\mathbf{5 0 m}$ & $\mathbf{7 5 m}$ & $\mathbf{1 0 0 m}$ & Total & Porções 2 e 3 \\
\hline Atleta A & 18 & 21 & 23 & 24 & 86 & 44 \\
Atleta B & 19 & 20 & 22 & 23 & 84 & 42 \\
Atleta C & 15 & 19 & 20 & 22 & 76 & 39 \\
Atleta D & 17 & 19 & 20 & 22 & 78 & 39 \\
Atleta E & 17 & 21 & 22 & 26 & 86 & 43 \\
Atleta F & 23 & 26 & 28 & 29 & 106 & 54 \\
Atleta G & 27 & 29 & 30 & 31 & 117 & 59 \\
Atleta H & 22 & 27 & 29 & 32 & 110 & 56 \\
Atleta I & 18 & 21 & 24 & 26 & 89 & 45 \\
Atleta J & 26 & 31 & 33 & 35 & 125 & 64 \\
Atleta K & 16 & 19 & 20 & 22 & 77 & 39 \\
Atleta L & 30 & 35 & 37 & 37 & 139 & 72 \\
Atleta M & 19 & 23 & 24 & 26 & 92 & 47 \\
Atleta N & 15 & 16 & 19 & 20 & 70 & 35 \\
Atleta O & 19 & 22 & 24 & 25 & 90 & 46 \\
\hline MÉDIA & 20,06 & 23,26 & 25 & 26,66 & 95 & 48,26 \\
\hline
\end{tabular}


TABELA 3 - Tempos de nado: mesociclo de transformação

\begin{tabular}{|c|c|c|c|c|c|}
\hline Atleta/Tempo & $25 \mathrm{~m}$ & $50 \mathrm{~m}$ & $75 \mathrm{~m}$ & $100 \mathrm{~m}$ & Total \\
\hline Atleta A & $13 ', 86$ & 16 '’32 & $16 " 48$ & 17 '17 & 1'03'83 \\
\hline Atleta B & $15 " 18$ & $17 ' \prime 15$ & $18{ }^{\prime \prime} 21$ & $18^{\prime} 27$ & $1^{\prime} 00^{\prime \prime} 01$ \\
\hline Atleta C & $14 \times 45$ & 16 " 46 & 17 '27 & $17 ' 48$ & $1{ }^{\prime} 05^{\prime \prime} 66$ \\
\hline Atleta D & $14 \times 15$ & $16^{\prime} 23$ & 17 '35 & $17 ' 56$ & $1^{\prime} 05^{\prime \prime} 29$ \\
\hline Atleta E & $13 '>87$ & 16 '”32 & 17 '35 & $17 ' 35$ & 1'04'"89 \\
\hline Atleta F & $17 ’ 94$ & $21 " ' 54$ & $21{ }^{\prime \prime} 33$ & $22 " 31$ & $1 ' 23^{\prime \prime} 12$ \\
\hline Atleta G & $17^{\prime \prime} 62$ & $18^{\prime \prime} 24$ & 19 "'13 & $19 ' 56$ & 1'14"55 \\
\hline Atleta $H$ & $19^{\prime \prime} 73$ & 23 '’76 & 25 ' 78 & $26^{\prime \prime} 14$ & $15^{\prime \prime} 37$ \\
\hline Atleta I & $15^{\prime \prime} 00$ & 16 "' 86 & 17 '99 & $18 ' 29$ & $1^{\prime} 08^{\prime \prime} 14$ \\
\hline Atleta $\mathbf{J}$ & 19 '84 & 22 '"42 & $24 " 41$ & $26 ’ 10$ & 1'32'77 \\
\hline Atleta K & $12 " 89$ & 14 '"79 & 15 "17 & 15,38 & $58^{\prime \prime} 23$ \\
\hline Atleta $L$ & $18^{\prime \prime} 03$ & 21 ''12 & 23 " 14 & $24 ' 82$ & $1^{\prime} 27^{\prime \prime} 11$ \\
\hline Atleta M & $18 ’ 19$ & 22 '”0 & 22 ' 78 & $20 ’ 69$ & 1'23"66 \\
\hline Atleta N & $14 " 48$ & $16 "$ "52 & $16 " 98$ & $17^{\prime \prime} 01$ & $1^{\prime} 04^{\prime} 99$ \\
\hline Atleta 0 & $17 ’ 14$ & $18^{\prime \prime} 63$ & 21 '”4 & $20 ’ 19$ & $1^{\prime} 17^{\prime \prime} 00$ \\
\hline MÉDIA & $16^{\prime \prime} 15$ & $18^{\prime \prime} 72$ & $19 " 62$ & $19^{\prime \prime} 88$ & 1'14"39 \\
\hline
\end{tabular}

TABELA 4 - Números de braçadas: mesociclo de transformação

\begin{tabular}{lcccccc}
\hline Atleta/Tempo & $\mathbf{2 5 m}$ & $\mathbf{5 0 m}$ & $\mathbf{7 5 m}$ & $\mathbf{1 0 0 m}$ & Total & Porções 2 e 3 \\
\hline Atleta A & 18 & 21 & 22 & 23 & 84 & 43 \\
Atleta B & 19 & 20 & 22 & 23 & 84 & 42 \\
Atleta C & 16 & 19 & 21 & 23 & 79 & 40 \\
Atleta D & 17 & 18 & 21 & 22 & 78 & 39 \\
Atleta E & 17 & 18 & 21 & 22 & 78 & 39 \\
Atleta F & 23 & 24 & 25 & 26 & 98 & 49 \\
Atleta G & 27 & 28 & 29 & 30 & 114 & 57 \\
Atleta H & 21 & 28 & 29 & 30 & 108 & 57 \\
Atleta I & 19 & 21 & 22 & 25 & 87 & 43 \\
Atleta J & 26 & 31 & 33 & 35 & 125 & 64 \\
Atleta K & 15 & 18 & 19 & 20 & 72 & 37 \\
Atleta L & 28 & 32 & 34 & 37 & 131 & 66 \\
Atleta M & 19 & 23 & 24 & 25 & 91 & 47 \\
Atleta N & 15 & 16 & 19 & 20 & 70 & 35 \\
Atleta O & 19 & 22 & 23 & 23 & 87 & 45 \\
\hline MÉDIA & 19,93 & 22,6 & 24,26 & 25,6 & 92,4 & 46,86 \\
\hline
\end{tabular}


TABELA 5 - Tempos de nado - mesociclo de transformação

\begin{tabular}{|c|c|c|c|c|c|}
\hline Atleta/Tempo & $25 m$ & $50 \mathrm{~m}$ & $75 m$ & $100 \mathrm{~m}$ & Total \\
\hline Atleta A & 13 '’84 & 16 '’16 & $16^{\prime \prime} 28$ & 16 '92 & $1^{\prime} 03^{\prime \prime} 20$ \\
\hline Atleta B & $15 ’ 24$ & 16 '96 & 17 '94 & $18 ’ 19$ & $1^{\prime} 00^{\prime \prime} 33$ \\
\hline Atleta C & $14{ }^{\prime} 03$ & $15^{\prime \prime} 34$ & $17 ', 12$ & 16 '’98 & $1^{\prime} 03$ ' 47 \\
\hline Atleta D & 14 '’17 & 16 '’05 & 16 '’94 & $17^{\prime \prime} 32$ & $1^{\prime} 04^{\prime \prime} 48$ \\
\hline Atleta E & 13 '’81 & $15^{\prime \prime} 38$ & 16 '’98 & $17 ', 17$ & $1^{\prime} 03^{\prime \prime} 34$ \\
\hline Atleta F & $17 ', 86$ & 20 ' 68 & $21 ', 45$ & $22 ’ ’ 07$ & $1^{\prime} 22^{\prime \prime} 06$ \\
\hline Atleta G & 17 '’21 & 18 '’28 & $18, ' 87$ & 19 '’11 & $1^{\prime} 13^{\prime \prime} 47$ \\
\hline Atleta $\mathbf{H}$ & $14, ' 51$ & 16 '’29 & 17 ''15 & $17 ', 59$ & $1 ' 34^{\prime \prime} 62$ \\
\hline Atleta I & $14, ' 51$ & 16 '’29 & $17 ' \prime 15$ & $17 ', 59$ & $1^{\prime} 05^{\prime \prime} 54$ \\
\hline Atleta J & $18 ', 32$ & $21 ', 04$ & 23 '’36 & 24 '’99 & $1^{\prime} 27^{\prime \prime} 71$ \\
\hline Atleta K & $12 ’ 74$ & $14 ' ’ 77$ & $15, ' 16$ & $15^{\prime \prime} 22$ & $57^{\prime \prime} 89$ \\
\hline Atleta L & $17^{\prime \prime} 33$ & 19 '’30 & $21 " ' 62$ & 23'’93 & $1^{\prime} 22^{\prime \prime} 18$ \\
\hline Atleta M & 17’59 & $21 " ' 69$ & $22{ }^{\prime \prime} 23$ & $20 ’ 21$ & $1^{\prime} 21^{\prime \prime} 72$ \\
\hline Atleta N & 14 '”42 & $15^{\prime \prime} 92$ & 16 '’84 & 16 ' 88 & $1^{\prime} 04^{\prime \prime} 06$ \\
\hline Atleta $\mathbf{O}$ & 16 '’98 & $18 ', 46$ & 20 '’7 & 20 '’98 & 1'16"69 \\
\hline MÉDIA & $15^{\prime \prime} 35$ & $17^{\prime \prime} 50$ & $18^{\prime \prime} 62$ & $19^{\prime \prime} 01$ & $1^{\prime} 10^{\prime \prime} 49$ \\
\hline
\end{tabular}

TABELA 6 - Números de braçadas: mesociclo de realização

\begin{tabular}{ccccccc}
\hline Atleta/Tempo & $\mathbf{2 5 m}$ & $\mathbf{5 0 m}$ & $\mathbf{7 5 m}$ & $\mathbf{1 0 0 m}$ & Total & Porções 2 e 3 \\
\hline Atleta A & 18 & 20 & 21 & 23 & 82 & 41 \\
Atleta B & 19 & 20 & 21 & 22 & 82 & 41 \\
Atleta C & 16 & 19 & 21 & 23 & 79 & 40 \\
Atleta D & 17 & 19 & 20 & 21 & 77 & 39 \\
Atleta E & 17 & 21 & 22 & 26 & 86 & 43 \\
Atleta F & 20 & 22 & 23 & 25 & 90 & 45 \\
Atleta G & 26 & 29 & 30 & 31 & 116 & 59 \\
Atleta H & 29 & 30 & 32 & 34 & 125 & 62 \\
Atleta I & 18 & 21 & 24 & 26 & 89 & 45 \\
Atleta J & 26 & 31 & 33 & 35 & 125 & 64 \\
Atleta K & 15 & 18 & 19 & 20 & 72 & 37 \\
Atleta L & 26 & 29 & 33 & 35 & 123 & 62 \\
Atleta M & 25 & 28 & 29 & 30 & 112 & 57 \\
Atleta N & 15 & 17 & 19 & 20 & 71 & 36 \\
Atleta O & 18 & 20 & 21 & 21 & 80 & 41 \\
\hline MÉDIA & 20,33 & 22,93 & 24,53 & 26,13 & 93,93 & 47,46 \\
\hline
\end{tabular}


Comparando o tempo da prova de 100 metros livre em cada mesociclo da estruturação de treinamento ATR, nota-se uma evolução voltada à diminuição do tempo total (Tabelas 1,3 e 5 e Figura 1). No primeiro mesociclo, de acumulação, seus tempos se apresentam maiores que nos outros mesociclos. No de transformação essas marcas diminuem e no terceiro e último mesociclo, de realização, esse tempo diminui de maneira mais acentuada. Percebe-se, dessa forma, uma diminuição do tempo do primeiro para o segundo, e para o terceiro mesociclo, consecutivamente. Nota-se que, embora com variações na intensidade das variações de tempo, a diminuição das marcas de todos os atletas se mostra como uma constante durante as análises.

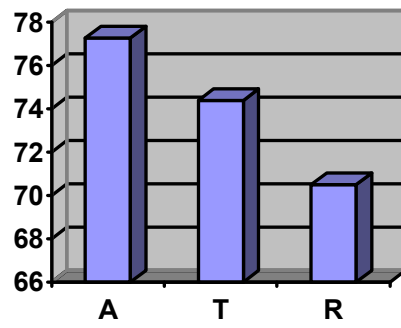

$\square$ Tempo de prova

por segundos

FIGURA 1: Evolução de tempos de nado de todos os atletas em segundos.

No que diz respeito ao tempo parcial e ao número de braçadas dos atletas a cada 25 metros, nota-se que, nos três mesociclos, todos utilizaram uma única tendência de prova, na qual os primeiros 50 metros foram executados de forma mais rápida, e os últimos 50 de forma mais lenta. O mesmo comportamento se observou em relação aos números de braçadas.

Nota-se que o número total de braçadas dos atletas durante a prova praticamente não varia durante todo $\mathrm{o}$ macrociclo, assim como nas porções intermediárias (2 e 3), sem a interferência dos processos de saída e chegada (FIGURA 2). Esse é um indicador de que as melhoras de rendimento dos mesmos deram-se com base em adaptações fisiológicas e neurológicas, proporcionadas pela periodização em ATR. 


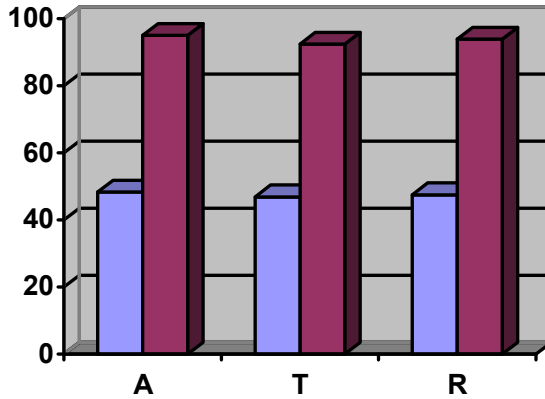

Graçadas em porções intermediárias da prova (2 e 3)

-Total de braçadas na prova

FIGURA 2 - Evolução de número de braçadas de todos os atletas.

Tal comportamento, que indica homogeneidade em relação ao esforço de todos os atletas na prova, e valida a análise, se mostra homogêneo entre os 15 sujeitos analisados.

Se tomada como referência para análise dos tempos o critério de maior importância para as parciais intermediárias dos 100 metros, nota-se também que as médias dos atletas apresentam sempre uma ação mais lenta na terceira porção da prova, em relação à segunda porção. Isso comprova que, mesmo isolando o início e final da prova, os atletas apresentaram certa queda de rendimento na segunda metade da mesma.

Com base na análise dos dados, pode-se observar que, conforme esperado por Navarro (1994), os atletas apresentaram melhoras de rendimento graduais no decorrer do macrociclo, tendo maior evolução em relação à especificidade de sua prova no mesociclo de realização.

Tal análise, com base no processo de treinamento e competição dos atletas da equipe analisada, comprova que o método citado se mostrou adequado para o treinamento desses nadadores. Proporcionando a eles sensível melhora em seus rendimentos atléticos.

\section{CONSIDERAÇÕES FINAIS}

O presente estudo examinou a natação competitiva em seu aspecto técnico, com ênfase no desenvolvimento de periodização do treinamento através de um planejamento prévio. Ao observar os resultados, pode-se constatar uma melhora no tempo dos atletas nos três mesociclos e competições analisadas. 
Identificou-se que os atletas otimizaram suas performances atingindo melhores marcas nos mesociclos de uma maneira progressiva, marcando seu pior tempo no mesociclo de acumulação, um tempo intermediário no mesociclo de transformação e seu melhor tempo no mesociclo de realização.

Observou-se também que os nadadores seguiram de uma mesma tendência nos três mesociclos, nadando os primeiros 50 metros num tempo menor que na segunda metade de prova. Isso justifica que o grupo de nadadores agiu de forma homogênea durante as provas, validando a análise.

Conclui-se, segundo as observações realizadas durante a pesquisa, que a estruturação de treinamento ATR que foi aplicada aos nadadores contribuiu de forma positiva para a melhora de suas performances. Desse modo, cabe o questionamento em relação à eficácia da aplicação desse mesmo método para outros tipos de provas, mais longas, por exemplo. Ponto esse que merece atenção em estudos posteriores.

\section{REFERÊNCIAS}

BOMPA, T. O. A periodização do treinamento esportivo. São Paulo: Manole, 2001. . Periodização: teoria e metodologia do treinamento. São Paulo: Phorte, 2002.

DANTAS, E. H. M. A prática da preparação fisicica. 3. ed. Rio de Janeiro: Shape, 1995.

GARCIA MANSO, J. M. Bases teóricas del entrenamiento deportivo. Madrid: Gymnos, 1996.

MATVEEV, L. P. Metodologia do treinamento: treino desportivo. Guarulhos: Phorte, 1997.

NAVARRO, F. V. La resistência. Madrid: Gymnos, 1994.

Agradecimento

À equipe de natação APAN de Bragança Paulista, e sua comissão técnica. 


\section{Renato Francisco Rodrigues Marques}

Fundação Municipal de Ensino Superior de Bragança Paulista

Thamy Guazelli Ambrósio

Fundação Municipal de Ensino Superior de Bragança Paulista

\section{Gabriela Fabrega Menin}

Fundação Municipal de Ensino Superior de Bragança Paulista

\section{Orival Andries Junior}

Faculdade de Educação Física - UNICAMP

\section{Referência do artigo:}

ABNT

MARQUES, R. F. R. et al. Análise de rendimento atlético em aplicação do método de periodização ATR para nadadores de provas de 100 metros nado livre. Conexões, v. 7, n. 2, p. 64-78, 2009.

APA

Marques, R. F. R., Ambrosio, T. G., Menin, G. F., \& Andries Junior, O. (2009). Análise de rendimento atlético em aplicação do método de periodização ATR para nadadores de provas de 100 metros nado livre. Conexões, 7(2), 64-78.

\section{VANCOUVER}

Marques RFR, Ambrosio TG, Menin GF, Andries Junior O. Análise de rendimento atlético em aplicação do método de periodização ATR para nadadores de provas de 100 metros nado livre. Conexões, 2009; 7(2): 64-78.

Recebido em: 25/04/2009

Aceito para publicação em: jul. 2009 